\title{
FACTORS INFLUENCING NEW GRADUATES' START-UP INTENTIONS IN ENGINEERING TECHNOLOGY IN CAN THO CITY
}

\author{
Huynh Canh Thanh Lam ${ }^{1}$, Nguyen Minh Tan ${ }^{2}$, Huynh Thanh $\mathrm{Nha}^{3}$
}

\begin{abstract}
This study aims to find what factors influence new graduates' start-up intentions in the field of Engineering Technology in the city of Can Tho. Surveys were completed by 400 new graduates from universities in the area with Cronbach's Alpha test method, exploratory factor analysis, and multiple linear regression were utilized in order to examine the relationships among the factors and the new graduates' start-up intentions. The results showed that factors influencing new graduates' start-up intentions comprise of attitudes, external factors and subjective thinking.
\end{abstract}

Keywords: Can Tho City, engineering technology, new graduates, start-up intention.

\section{INTRODUCTION}

In the era of Industry 4.0, and the rapid development of high technology, the world economy develops in the tendency of globalizing an academic economy. However, these developments lead to a machine labor economy and an increase of unemployment. Recently, new graduates' startups in Vietnam especially in the Mekong Delta including Can Tho, new graduates' start-ups are struggling. This study analyzed factors influencing new graduates' start-up intentions in the field of Engineering Technology in Can Tho. Accordingly, this study established and examined the scale reliability of new graduates' start-up intentions, exploratory factor analysis, and multiple linear regression in order to estimate factors influencing new graduates' start-up intentions in the field of Engineering Technology in the city region. As a result, the study recommends some measures to enhance new graduates' start-up intentions in the field of Engineering Technology.

\footnotetext{
${ }^{1}$ Can Tho Technical Economic College

${ }^{2,3}$ Can Tho University of Technology

Email: hctlam@ctec.edu.vn

Received date: $13^{\text {th }}$ December 2020; Revised date: $13^{\text {th }}$ January 2021; Accepted date: $20^{t h}$ January 2021
}

\section{RESEARCH CONTENT}

\section{A. Theoretical literature reviews}

1) Theory of start-up intentions: Subject of this study is new graduates' start-up intentions; Schwarz et al. [1] assume that students' startup intentions originate from students' ideas and decent orientation of educational programs and educators. Additionally, Kuckertz and Wagner [2] insist that students' start-up intentions is an individual's intention originating from his or her realization of opportunities, ready resources and support from the environment in order to establish his or her own business. Besides, according to Krueger et al. [3], start-up intention signals one's efforts and preparation to activate a business.

2) Theoretical frameworks and factors influencing start-up intentions: Students' start-up intentions are affected by several factors and aspects. This study examined three principles.

First, the quality of students' start-ups is connected to start-up educational programs. This program enriches students' knowledge and skills of the start-up procedure. According to Taatila and Down's study [4], students from different training programs tend to start up differently. Students who have previous experience with businesses tend to start up better than students with no experience. Students who think positively about start-ups tend to start up better than students who think negatively about it.

Second, national culture plays an important role in the establishment and utilization of social capital. Therefore, students in different countries have different start-up intentions [5]. On the other hand, parents' professions would influence their children's choice of careers. Parents who do their own businesses are typical examples and this boosts the process of starting up, whereas parents who work in public sectors are not an example and prevent their children from starting up [6]. 
Third, about motives, factors categorized as motives could influence start-up intentions such as: demands for success, desire for independence, and ambitions to achieve one's goals [7]. Among these, the factor that demands success affects the outcome positively - to do business start-ups and do business successfully [8], [9]. About personality, characteristics such as accepting risks, beliefs in one's ability, self-control, tolerance of ambiguity, passions, efforts, and good vision are connected with students' start-up intentions. Moreover, readiness to change, being proactive, belief in one's ability, pressure tolerance, demand of autonomy, and self control positively influence business establishment and success. Additionally, creativity, self control, and belief in one's ability are positively connected to students' start-up intentions [10], [5]. Nguyen and Phan's study [11] showed that enthusiasm, open-mindedness, responsibility, and honesty are characteristics that a young start-up person needs. About reasoning, start-up reasoning is the ability to become active, flexible and adjustable in one's awareness in order to adapt to unsure and dynamic environments [12]. About attitude, based on the theory of planning behavior (TPB) of Ajzen [13], previous studies which established a model of factors influencing students' start-up intentions showed that attitudes towards start-up and control evaluation relevant to behaviors both positively influence students' start-up intentions [14]. Besides, attitude towards start-up and effective self evaluation both positively influence students' start-up intentions [15]. Next, a study of Yurtkoru et al. [16] showed that the attitude towards start-ups and control evaluation relevant to behaviors have an effective impact on start-up intentions. In regards to genders, females have a higher influence in start-up intentions compared to males [17]. However, Nicolaou and Shane [18] concluded that no difference was found between males' and females' start-up intentions. Nevertheless, Maes et al. [19] proved that personal attitudes explained that females' start-up intention is weaker than that of males. Controlling behaviors explained that females' start-up intention is weaker than that of males because females desire to balance social values more than males do (saving time for family, and children); consequently, women gain less achievements in starting-up compared to men.

3) Empirical evidence reviews: Robinson [20] showed that positive thinking affects students' start-up intentions; and confidence and selfsatisfaction are factors. On the other hand, Delmar and Davidsson [15] indicated that they are also influenced by outstanding factors like age, gender, educational background, work experience, education history and personal factors. Examining more deeply, Mair and Noboa [21] pointed out that social start-up intentions started from moral awareness to true empathy. Results showed that moral factors are key factors. Accordingly, the researchers showed that main approaches of start-up intentions include: educational program, environmental impact, and the learners themselves (motives, personality, reasoning, attitude, and gender). Besides, Zain et al. [22] showed that factors like participation in business courses, influence from business tradition of family members and personal characteristics affect start-up intentions of Malaysian students majoring in economics. Fatoki [9] revealed factors influencing students' intentions including careers, freedom, creativity, economy, and capital. Obstacles for business purposes of new graduates are capitals, skills, and support. Wang et al. [23] pointed out that specific factors influencing students' start-ups comprised of business ambition, business readiness, work experience, family tradition of doing business, and business morality directly affect students' start-up intentions. Additionally, Perera et al. [24] showed that factors influencing students' start-ups were social, psychological, economic, political, and jurisdiction. Pruett et al. [25] indicated that there are also other factors influencing students' start-up intentions such as: external and environmental factors, family support, start-up examples, national culture, social capital, and social factors. The study of Francisco et al. [12] also showed that there are also 5 major factors affecting students' start-up intentions like readiness to do business, personal attitude, planning and league, growth key to success, priorities for useful work which influence students' start-up intentions in Spain. 
Relevant to more specific studies about start-up intentions related to training majors, Astebro et al. [26] proved that in The United States start-ups are not only a program for business students, but also an important program for students majoring in natural science, technology, and even in art. Besides, subjective norms, awareness of planning behaviors, and personal attitude towards becoming an entrepreneur also positively affect social business intentions. Phan Anh Tu and Giang Thị Cam Tien [27] noted that there are 5 factors influencing students' start-ups including: attitude and effectiveness, education and start-up opportunities, capitals, subjective norms, and awareness of planning behaviors. Another study more general about start-ups in Vietnam of Begley and Tan [28] showed that family values and ideas play a key role especially in collectivistic cultures; so every individual's independence, especially individuals who are still at school, unemployed, and dependent upon their parents', their siblings' and friends' ideas play a significant role in what an individual desires to do. For instance, if an individual wants to initiate a start up, this intention is a big step in every individual's life and affected by their close family and friends opinions.

\section{B. Research model}

1) Theoretical framework: Based on the previous theory and relevant studies, the theoretical research model about factors influencing new graduates' start-up intentions in the field of Engineering Technology in Can Tho City is suggested as follows:

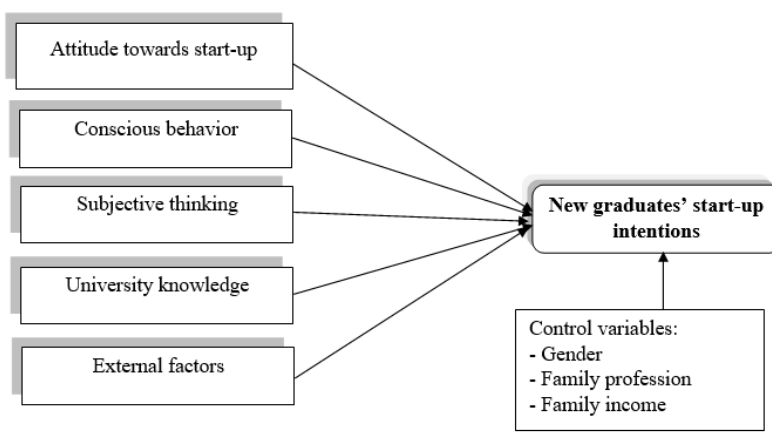

Fig. 1: Suggested theoretical research model

(Source: Compiled by authors in 2020)
2) Experimental research model: Multiple linear regression was conducted in order to examine the influence of factors to new graduates' startup intentions - the research model was written in the following form:

$Y\left(Y(\mathrm{E} K N)=\beta_{0}+\beta_{1} F 1+\beta_{2} F 2+\ldots+\beta_{k} F k\right.$

In this form: Y (YDKN) is a dependent variable of new graduates' start-up intentions; $\mathrm{Y}$ is the average mean of observable variables of "start-up intention" factors.

$F 1, F 2, \ldots, F k$ are independent variables which were formulated from extracted factors $(\mathrm{k}$ is the number of factors).

$\beta_{0}$ is estimated value of $\mathrm{Y}$ when $\mathrm{k}$ of $\mathrm{F}$ variable equals

$\beta_{1}, \beta_{2}, \ldots, \beta_{k}$ are regression coefficients

\section{Results}

1) Results of reliability test: Cronbach's Alpha test results show that, for factors in the group of independent variables, from 19 initial observed variables, the remaining test results 17 observed variables are eligible for analysis. In addition, the student's Entrepreneurship Intent scale with 4 observed variables satisfies the conditions to perform the next discovery factor analysis step.

2) Results from exploratory factor analysis: Results from exploratory factor analysis of 17 observable variables are eligible after Cronbach's alpha test method, displayed in Table 1.

Results from exploratory factor analysis satisfy 4 steps of accreditation, specifically:

(1) Factor loading of observable factors gains from $0.552-0.917$, bigger than 0.5 ; this proved that these observable factors are reliable.

(2) $\mathrm{KMO}$ coefficient $=0.746>0.5$, satisfying Eigenvalue of factor analysis if $0.5 \leq \mathrm{KMO} \leq 1$ [29].

(3) Coefficient Sig. $=0.000<0.005$ of Bartlett test showed that there are observable factors correlating with general meaningful statistics; accordingly, the observations are compatible with factor analysis.

(4) Average Variance Extracted, according to Gerbing and Anderson [30], this accumulated variance is bigger than $50 \%$ which is suitable for factor analysis. The accumulated variance result $=75.163 \%$; this means that $75.163 \%$ variance is explained by factors. 
Table 1: Results from exploratory factor analysis

\begin{tabular}{|c|c|c|c|c|c|}
\hline \multirow{2}{*}{ Observable variables } & \multicolumn{5}{|c|}{ Factors } \\
\hline & F1 & F2 & F3 & F4 & F5 \\
\hline YTHV5 & 0.917 & & & & \\
\hline YTHV6 & 0.916 & & & & \\
\hline YTHV8 & 0.812 & & & & \\
\hline YTHV9 & 0.790 & & & & \\
\hline YTNC19 & & 0.823 & & & \\
\hline YTNC17 & & 0.794 & & & \\
\hline YTNC18 & & 0.793 & & & \\
\hline YTNC16 & & 0.552 & & & \\
\hline THAIDO2 & & & 0.872 & & \\
\hline THAIDO1 & & & 0.813 & & \\
\hline THAIDO3 & & & 0.697 & & \\
\hline THAIDO4 & & & 0.692 & & \\
\hline KTĐH13 & & & & 0.904 & \\
\hline КТÐH14 & & & & 0.890 & \\
\hline SNCQ10 & & & & & 0.883 \\
\hline SNCQ11 & & & & & 0.868 \\
\hline \multicolumn{3}{|l|}{ Eigenvalue } & \multicolumn{3}{|r|}{1.094} \\
\hline \multicolumn{3}{|c|}{ Average Variance Extracted (\%) } & \multicolumn{3}{|r|}{75.163} \\
\hline \multicolumn{3}{|l|}{ KMO coefficient } & \multicolumn{3}{|r|}{0.746} \\
\hline \multicolumn{3}{|l|}{ Bartlett's Test } & \multicolumn{3}{|r|}{0.000} \\
\hline \multicolumn{3}{|l|}{ Observable number } & \multicolumn{3}{|r|}{400} \\
\hline
\end{tabular}

(Source: Data analysis of 400 new graduates' survey numbers in the field of Engineering Technology in Can Tho City in 2020)

Besides, Eigenvalue $=1.094>1$, this value indicated that exploratory factor analysis stopped at the fifth factor (F1 - F5).Therefore results from exploratory factor analysis showed that from 17 observable factors in five original scales extracted 5 new factors with 16 observable variables.

Exploratory factor analysis in Table 1 showed that there are 5 factors formulated with $16 \mathrm{ob}-$ servable variables (variable SNCQ12 is eliminated because its factor loading is smaller than $0.5)$.

3) Results from multiple regression analysis: After extracting factors F1-F5 and start-up intention factor $(\mathrm{Y})$, independent variables were put into the regression model by the Enter approach. Meanwhile, values of independent variables are calculated by average mean of observable variables of those factors while values of dependent variables are calculated by average mean of 5 independent variables of start-up intention scale.
Estimated results of linear regression model are displayed in Table 2.

In order to ensure that the used model is suitable, while doing regression analysis, the regulations of the linear regression model were checked. For example, multicollinearity is examined through variance inflation factor VIF. Accreditation results from Table 2 showed that the VIF coefficient of independent variables is from $1.013-1.634$, smaller than 2 (requirement is VIF < 10); therefore, the model does not exhibit multicollinearity. Also, results from accreditation indicated that the $\mathrm{F}$ coefficient of the model is 59.912 with level of significance $=$ 0.000 smaller than $\operatorname{sig} \alpha=1 \%$; this means that the linear regression model which is utilized is worth at $1 \%$. Coefficient $\mathrm{R}^{2}=0.436$, independent variables explained $43.6 \%$ of new graduates' start-up intentions in the field of Engineering Technology in Can Tho City. 
Table 2: Estimated results of linear regression model

\begin{tabular}{|l|c|c|c|c|c|}
\hline \multicolumn{1}{|c|}{ Variable } & B coefficient & $\begin{array}{c}\text { A standardized } \\
\text { Beta coefficient }\end{array}$ & $\begin{array}{c}\text { Standard } \\
\text { Error }\end{array}$ & $\begin{array}{c}\text { Statistical } \\
\text { significance }\end{array}$ & VIF \\
\hline F1: Conscious behavior & 0.010 & 0.014 & 0.033 & 0.762 & 1.410 \\
\hline F2: External factors & 0.100 & 0.131 & 0.037 & $0.008^{* * *}$ & 1.634 \\
\hline F3: Start-up attitude & 0.641 & 0.556 & 0.044 & $0.000^{* * *}$ & 1.011 \\
\hline F4: University knowledge & -0.024 & -0.039 & 0.027 & 0.379 & 1.329 \\
\hline F5: Subjective thinking & 0.237 & 0.332 & 0.027 & $0.000^{* * *}$ & 1.013 \\
\hline Blocking coefficient & 0.088 & & 0.243 & 0.717 & \\
\hline F coefficient & & \multicolumn{3}{|c|}{0.000 .912} \\
\hline The meaning of the model (Sig.) & \multicolumn{3}{|l|}{0.436} \\
\hline $\mathrm{R}^{2}$ & & &
\end{tabular}

(Note: ***: 1\%. Source: Data analysis of 400 new graduates' survey numbers in the field of Engineering Technology in Can Tho City in 2020)

Estimated results of linear regression model of factors influencing students' start-up intentions in Table 2 showed that among 5 variables put into the research model, there are 3 affected variables with statistical meaning to new graduates' start-up intentions in the field of Engineering Technology in Can Tho City, variables are: F2 (external factors); F3 (start-up attitude) and F5 (subjective thinking). Whereby, variables affected at $1 \%$ level of significance (level of sig. $<\alpha$ $=0.01)$. Moreover, these variables corresponded positively with the students' start-up intentions. This finding is correlated with hypotheses and compatible with findings of previous studies such as: Ajzen [13]; Pruett et al. [25]; Francisco et al. [12].

On the other hand, two factors F1 (conscious behavior) and F4 (university knowledge) is at level of significance sig.> $\alpha=10 \%$; thus, these two factors are meaningless statistically to new graduates' start-up intentions in the field of Engineering Technology in Can Tho City. This finding is not correlated with hypothesis and not compatible with previous studies. Therefore, when being asked about start-up intentions, these students are not interested in factors of conscious behavior and university knowledge; many students think that attitude towards start-up intentions, external factors and subjective thinking strongly affect new graduates' start-up intentions.

Results of research model is displayed in Figure 2.

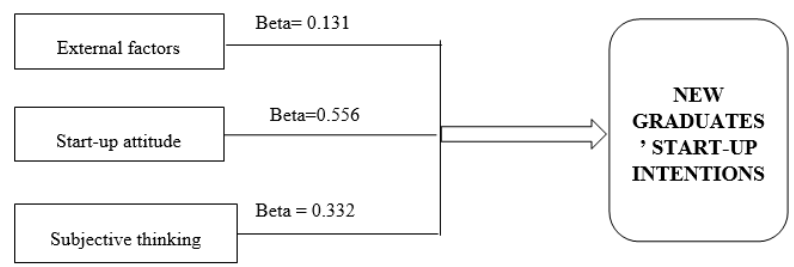

Fig. 2: Factors influencing new graduates' start-up intentions

(Source: compiled from findings of linear regression analysis)

The results of this study are consistent with the hypothesis set forth and similar to the research results of some previous studies such as: Ajzen [13]; Pruett et al. [25]; Francisco et al. [12]; Phan Anh Tu et al. [27].

\section{CONCLUSIONS}

Start-up intentions express students' awareness, opinions, and creativity when they are at university, initiating their start-up intentions in the future. The findings indicated that there are 3 influencing variables with statistical meaning of students' start-up intentions comprising of: external factors, start-up attitude and subjective thinking. All variables have positively affected students' start-up intentions and carry statistical meaning at the level of $1 \%$. Factors influencing students' start-up intentions is a base to suggest four groups of practical recommendations, improving start-up environment, and creating jobs 
for students after graduation. This is one of the most important issues that society and student families pay attention to, helping the society develop and creating job opportunities for the students themselves and the social community.

\section{REFERENCES}

[1] E. J.Schwarz, M. A.Wdowiak, D. A. Almer-Jarz, R. J. Breitenecker. The effects of attitudes and perceived environment conditions on students' entrepreneurial intent: An Austrian perspective. Education + Training. 2009; 51(4):272-291.

[2] Kuckertz, M . Wagner. The influence of sustainability orientation on entrepreneurial intentions - Investigating the role of business experience. Journal of Business Venturing. 2010; 25(5):524-539.

[3] N. F. Krueger, M. D. Reilly, A. L. Carsrud. Competing models of entrepreneurial intentions. Journal of business venturing. 2000; 15(5):411-432.

[4] V. Taatila, S. Down. Measuring entrepreneurial orientation of university students. Education Training. 2012; 54(8):744-760.

[5] H. Sesen. Personality or environment? A comprehensive study on the entrepreneurial intentions of university students. Education + Training. 2013; 55(7):624640.

[6] Pablo-Lerchundi, G. Morales-Alonso, R. M. González-Tirados. Influences of parental occupation on occupational choices and professional values. Journal of Business Research. 2015; 68(7):16451649.

[7] S. Shane, E. A. Locke, C. J. Collins. Entrepreneurial motivation. Human Resource Management Review. 2003; 13(2):257-279.

[8] J.P. Boissin, B. Branchet, S. Emin, J. I. Herbert. Students and Entrepreneurship: A Comparative Study of France and the United States. Journal of Small Business \& Entrepreneurship. 2009; 22(2):101-122.

[9] Fatoki Olawale Olufunso. Graduate Entrepreneurial Intention in South Africa: Motivations and Obstacles. Department of Business Management. University of Fort Hate; 2010.

[10] Hoang Trong, Chu Nguyen Mong Ngoc. Research data analysis in SPSS. Hong Đuc Publisher; 2008.

[11] M. Nguyen, A. Phan. Entrepreneurial Traits and Motivations of the Youth - an Empirical Study in Ho Chi Minh City - Vietnam. International Journal of Business and Social Science. 2014; 5(1):53-62.

[12] Francisco Liñán, Juan Carlos Rodriguez- Cohad, José M.Rueda- Cantuche. Factors Affecting entrepreneurial intention levels, a role for education. International Entrepreneurship and Management Journal. 2011; 7(2):195-218.

[13] I.Ajzen. The theory of planned behavior. Organizational behavior and human decision processes.1991; 50(2):179-211.
[14] S. Wu, L .Wu. The impact of higher education on entrepreneurial intentions of university students in China. Journal of Small Business and Enterprise Development. 2008; 16(4):752-774.

[15] Delmar. Frédéric, Per Davidsson. Where do they come from? Prevalence and characteristics of nascent entreprencurs. Entreprencurship and Religional Development. 2000; 12(4):1-23.

[16] E.S.Yurtkoru, Z. K. Kuscu, A. Doganay. Exploring the Antecedents of Entrepreneurial Intention on Turkish University Students. Procedia - Social and Behavioral Sciences. 2014; 150:841-850.

[17] D. M. Sullivan, W. R. Meek. Gender and entrepreneurship: a review and process model. Journal of Managerial Psychology. 2012; 27(5):428-458.

[18] N. Nicolaou, S. Shane. Entrepreneurship and occupational choice: Genetic and environmental influences. Journal of Economic Behavior \& Organization. 2010; 76 (1):3-14.

[19] J. Maes, H. Leroy, L. Sels. Gender differences in entrepreneurial intentions: A TPB multi-group analysis at factor and indicator level. European Management Journal. 2014; 32(5):784-794.

[20] P. B. Robinson. Prediction of entrepreneurship based on attitude consistency model. Unpublished doctoral dissertation, Brigham Young University. In Dissertation Abstracts International. 1987; (48):2807B.

[21] Mair Noboa. Social entrepreneurship: How intentions to create a social venture are formed. In Social entrepreneurship. UK: Palgrave Macmillan, 2006:121135.

[22] Zahariah Mohd Zain, Amalina Mohd Akram, Erlane K Ghani. Entrepreneurship intention among Malaysia Business Students. Canadian Social Science. 2010; 6(3): 34-44.

[23] Wenjun Wang, Wei Lu, John Kent Millington. Determinants of Entrepreneurial Intention among college students in China and USA. Journal of Global Entrepreneurship Research. 2011; 1(1):35-44.

[24] K.H. Perera, L.C.H. Jayarathna, R.R.P.K. Gunarathna. The Entrepreneurial Intention of Undergraduates in Sri Lankan University. Faculty of Commerce and Management Studies. University of Kelaniya, SriLanka. 2011.

[25] M. Pruett, R. Shinnar, B. Toney, F. Llopis, J. Fox. Explaining entrepreneurial intentions of university students: a cross-cultural study. In International Journal of Entrepreneurial Behaviour \& Research. 2009; 15(6):571-594. DOI:10.1108/13552550910995443.

[26] T. Åstebro, N. Bazzazian, S. Braguinsky. Startups by recent university graduates and their faculty: Implications for university entrepreneurship policy. Research Policy. 2012; 41(4):663-677. DOI:10.1016/j.respol.2012.01.004.

[27] Phan Anh Tu, Giang Thi Cam Tien. Factors influencing start-up intentions: A case study of students of Economics and Business Administration School 
of Can Tho University. Can Tho University Science Magazine. 2015; 38:59-66.

[28] T.M. Begley, W.L.Tan. The Socio-cultural environment for entrepreneurship: a comparison between East Asian and Anglo-Saxon countries. Journal of International Business Studies. 2001; 32(3):537-547.

[29] Hair J.F., Anderson R.E., Tatham R.L., Black W. C. Multivariate Data Analysis. Fifth Edition. PrenticeHall Intenational, Inc; 1998.

[30] J. C. Anderson, D. W. Gerbing. Structural Equation Modeling in Practice: A Review and Recommended Two-Step Approach. Psychological Bulletin. 1988. 103(3):411-423. DOI: https://doi.org/10.1037/00332909.103.3.411. 